\title{
Neoadjuvant Systemic Therapy and the Surgical Management of Breast Cancer
}

\author{
Jennifer F. Waljee, MD, MPH, \\ Lisa A. Newman, MD, MPH, FACS*
}

Department of Surgery, Breast Care Center, University of Michigan, 1500 East Medical Center Drive, 3308 CGC, Ann Arbor, MI, USA

Neoadjuvant systemic therapy (also called primary systemic therapy or induction therapy) has become a valuable strategy in the multidisciplinary treatment approach to breast cancer. Once reserved for women diagnosed with locally advanced or inflammatory breast cancer, the tumor downstaging benefits of the neoadjuvant therapy sequence are increasingly offered to women diagnosed with early-stage disease as well. Most of the neoadjuvant studies reported to date have involved delivery of chemotherapy as the induction therapy regimen.

Neoadjuvant chemotherapy offers several advantages compared with traditional postoperative regimens. Invasive breast cancer patients have a significant risk of harboring occult micrometastatic disease in distant organs. Neoadjuvant chemotherapy allows for earlier exposure of these micrometastases to chemotherapeutic agents, and an observed response to chemotherapy in the primary breast disease site indicates that the regimen has effective antitumor activity. Additionally, for women who experience significant regression of their tumor, neoadjuvant chemotherapy can allow for a more conservative surgical procedure. Neoadjuvant therapy clinical trials offer the promise of a rapid and less-costly means for evaluating the effectiveness of novel systemic therapy agents when compared to conventional adjuvant therapy trials. The latter format requires many thousands of participating patients followed over many years, and is extremely labor-intensive.

Several issues pertinent to the optimal utilization of neoadjuvant systemic therapy remain subject to extensive scrutiny and discussion. Some of these questions have been addressed through completed clinical trials, and others

* Corresponding author.

E-mail address: lanewman@umich.edu (L.A. Newman). 
continue to generate debate. First, can disease progression occur if the preoperative regimen is ineffective? Does neoadjuvant therapy downstaging of the breast and axillary disease impair our ability to perform adequate tumor resections, or to make appropriate recommendations regarding adjuvant locoregional radiation? A final consideration is related to the fact that progress in the local and systemic treatment of breast cancer occur simultaneously. Although we would like for our patients to benefit from all of these advances, the oncologically-safest strategy for integrating these advances into a comprehensive management plan is not always clear. A perfect example of this dilemma is apparent in the controversy regarding integration of lymphatic mapping/sentinel lymph node (SLN) biopsy into neoadjuvant chemotherapy protocols. This article provides an overview of neoadjuvant chemotherapy, and its influence on current surgical management for breast cancer. An accompanying article on Locally Advanced Breast Cancer in this issue of Surgical Clinics of North America addresses several of these issues as well.

\section{Indications for neoadjuvant chemotherapy}

Neoadjuvant chemotherapy was initially explored several decades ago for management of locally advanced and inflammatory breast cancer, as a strategy for improving local control of these high-risk cases by transforming inoperable disease into tumors that were amenable to resection. The use of neoadjuvant chemotherapy has recently been extended to women who have early-stage breast cancer to improve eligibility for BCS among women presenting with tumors that are bulky in proportion to their breast size and to allow for an in vivo assessment of tumor chemosensitivity. Therefore, any patient expected to require postoperative chemotherapy may be an appropriate candidate for neoadjuvant chemotherapy, regardless of tumor size [1]. However, recommendations for neoadjuvant chemotherapy will also be influenced the hormone receptor status, tumor grade, primary tumor histopathology, axillary nodal status, and patient age.

Although neoadjuvant chemotherapy has been studied most extensively with invasive ductal carcinoma, data are now emerging regarding outcome for invasive lobular breast cancers treated with neoadjuvant chemotherapy. Cristofanilli and colleagues [2] studied 122 patients who had invasive lobular carcinoma. Although these patients were more likely to present with advanced disease, and less likely to have a pathologic response to neoadjuvant chemotherapy, women who had invasive lobular carcinoma had longer overall survival and recurrence-free survival compared with women who had invasive ductal tumors. Similarly, Newman and colleagues [3] reported on feasibility of breast-conserving surgery in 100 women treated on a prospective clinical trial of neoadjuvant chemotherapy and found that invasive lobular histology was associated with a significantly lower likelihood of successful downstaging to lumpectomy eligibility when compared with invasive 
ductal carcinoma. Thus, women who have lobular tumors can be considered for neoadjuvant chemotherapy protocols, although their response may differ from that of women who have other tumor biology.

Although the potential applications for neoadjuvant chemotherapy are broad, there are some patients in whom this approach is contraindicated. Patients who have large-volume or palpable ductal carcinoma in situ (DCIS) tumors or DCIS tumors with microinvasion are not candidates for neoadjuvant chemotherapy. It is therefore important to obtain multiple core biopsy specimens in patients with mass lesions of the breast; the biopsies must confirm that the bulk of the tumor is comprised of invasive cancer in order to proceed with consideration of neoadjuvant chemotherapy. Although patients who have multifocal disease, multicentric disease, or extensive calcifications on mammography can be treated with neoadjuvant chemotherapy (and may benefit from the resulting assessment of tumor chemosensitivity), these patients should be aware that neoadjuvant chemotherapy is unlikely to offer them the possibility of BCS [3].

\section{Neoadjuvant chemotherapy regimens}

Although the optimal regimen has not been explicitly defined, anthracycline-based regimens are the most extensively studied in clinical trials. The typical approach consists of at least four to six cycles of an anthracyclinebased regimen, usually adriamycin and cyclophosphamide, with or without the addition of taxane-based agents. Several studies have reported higher pathologic clinical response rates and rates of BCS with the addition of preoperative docetaxel [4-6]. Other trials have explored the use of platinum agents, paclitaxel, and epirubicin in combination with anthracycline agents. Nonetheless, taxane and anthracycline regimens appear to be the most successful. Although a wide variety of timing schedules have been studiedsequential, concurrent, and dose-dense approaches-there is no consensus on the best timing for each chemotherapeutic agent $[1,7]$.

Preoperative endocrine therapy has been studied primarily in postmenopausal women who have endocrine-responsive disease, but the optimal integration of endocrine therapy into neoadjuvant chemotherapy protocols remains unclear. Although there are limited data on the use of preoperative endocrine therapy in premenopausal patients, estrogen-receptor status, specifically an Allred score of 6 or higher, has been advocated as the best measure to identify patients appropriate for neoadjuvant endocrine therapy $[8,9]$. Current data suggest that aromatase inhibitors may offer significantly better clinical response rates compared with tamoxifen, with higher rates of local response and rates of BCS [10]. At least 3-4 months of neoadjuvant endocrine therapy is generally delivered in order to achieve a significant clinical response. Achievement of a complete pathologic response is rare, occurring in fewer than $10 \%$ of cases in most reported studies. However, there are 
limited data regarding the addition of these agents into chemotherapeutic regimens and the extent to which they can offer additional survival benefit $[11,12]$. An ongoing prospective clinical trial conducted by the American College of Surgeons Oncology Group [13] is randomizing postmenopausal Stage II/III, estrogen receptor-positive breast cancer patients to receive sixteen weeks of one of the three different commercially-available aromatase inhibitors for sixteen weeks preoperatively. This trial will provide valuable insights regarding the downstaging effectiveness of neoadjuvant endocrine therapy for individual agents in a direct, head-to-head comparison.

\section{Neoadjuvant chemotherapy and outcomes}

\section{Tumor response and survival}

To date, several clinical trials comparing neoadjuvant chemotherapy with postoperative therapy have demonstrated equivalent survival for the two different treatment sequences. These studies have also shown that patients achieving a complete pathologic response (no residual invasive cancer identified in post-chemotherapy surgical specimen) have significantly higher survival rates compared to women with less than a complete response. These findings confirm the oncologic safety of neoadjuvant chemotherapy: outcome is not compromised by delaying the surgery while chemotherapy is delivered. They also support the concept that assessment of pathologic response to the neoadjuvant regimen is a valid surrogate marker of disease chemosensitivity. Additionally, rapid assessment of tumor response to the selected chemotherapy regimen provides an opportunity to individualize treatment. If the primary neoadjuvant chemotherapy regimen fails to result in a significant clinical response (indicating chemoresistant disease), then the oncology team then has an opportunity to switch to an alternative regimen (or proceed to surgery) and thereby minimize exposing the patient to the toxicity of an ineffective regimen. In practice however, little data is available to document the results from "crossover" regimens following suboptimal initial response in the neoadjuvant setting. The potential advantages of early crossover to alternative chemotherapy regimens may be realized as advances are made with preoperative imaging modalities to assess tumor response.

The National Surgical Adjuvant Breast and Bowel Project (NSABP) B-18 trial compared outcomes between patients receiving adjuvant and neoadjuvant chemotherapy, using survival and breast-conserving surgery as endpoints. In this study, more than 1500 women who had operable breast cancer were randomized to four cycles of doxorubicin and cyclophosphamide either pre- or postoperatively, with 9 years of follow-up now reported. There were no significant differences in overall survival or disease-free survival between women who received neoadjuvant chemotherapy and women who received adjuvant chemotherapy, with an overall survival for both groups was $70 \%$ at 9 years of follow up. Disease-free survival for both 
groups ranged between 53\% and 55\% [14]. Among women receiving neoadjuvant chemotherapy, tumor size was reduced in $80 \% ; 36 \%$ had a complete clinical response, and $13 \%$ had a complete pathologic response. Survival rates were significantly higher among the complete pathologic responders compared to other subsets [15].

Despite using a wide variety of chemotherapeutic agents, the majority of studies have shown that neoadjuvant chemotherapy offers similar overall survival and disease-free survival compared with adjuvant regimens. Several of these studies are summarized in Table 1. Both disease-free and overall survival from these studies range from $55 \%$ to $89 \%$, but within studies the survival rates are equivalent for the neoadjuvant and adjuvant randomization arms. Variation in survival rates is observed between studies, this is likely related to study design and the stage distribution of trial participants.

A recent meta-analysis by Mauri and colleagues [16] summarized nine randomized controlled trials that randomized women to either neoadjuvant or adjuvant chemotherapy. These authors report no difference in mortality between patients who received neoadjuvant chemotherapy, and patients who received adjuvant chemotherapy (summary relative risk of death $=$ $1.0,95 \%$ CI, 0.9-1.12). Additionally, these authors did not find a significant increase in disease progression or distant recurrence among women who received neoadjuvant chemotherapy; however, the authors report a $22 \%$ higher rate of loco-regional recurrence among women who receive neoadjuvant chemotherapy (95\% CI, 1.04-1.43).

Several studies have confirmed the NSABP B-18 trial evidence that the clinical and pathologic tumor response of the primary tumor to neoadjuvant chemotherapy is associated with improved long-term outcome. Kuerer and colleagues [17] retrospectively analyzed survival rates of 372 locally advanced breast cancer patients managed on two different prospective trials of neoadjuvant chemotherapy at the M.D. Anderson Cancer Center. A complete pathologic response occurred in $12 \%$, and five year survival was $89 \%$ for these patients, compared to only $64 \%$ in patients with lesser degrees of response. Von Minckwitz and colleagues [18,19] reported in 2005 that early response to induction chemotherapy within the first one to two cycles can identify those patients who will have a high likelihood of achieving complete pathologic response. Feldman and colleagues [20] studied 90 patients who had inflammatory and locally advanced disease, and reported that patients who had a pronounced response following induction chemotherapy had a longer disease-free survival compared with patients who had lesser degrees of response. Thus, achievement of a mastectomy specimen free of residual macroscopic tumor after preoperative chemotherapy is an excellent prognostic factor for a prolonged disease-free and overall survival. Poor overall survival is associated with advanced nodal disease, failure to respond to preoperative chemotherapy, and an increased $\mathrm{S}$ phase fraction of the primary tumor. Additionally, increased metastatic recurrence is associated with age younger than 35 years, large clinical tumor size $(>5 \mathrm{~cm})$, 
Table 1

Studies of neoadjuvant and adjuvant chemotherapy for breast cancer

\begin{tabular}{|c|c|c|c|c|c|c|c|c|c|c|c|c|}
\hline \multirow[b]{2}{*}{ Study } & \multirow[b]{2}{*}{$\mathrm{N}$} & \multirow[b]{2}{*}{ Stage } & \multirow[b]{2}{*}{ Regimen } & \multirow[b]{2}{*}{$\begin{array}{l}\text { Median } \\
\text { follow-up }\end{array}$} & \multicolumn{2}{|c|}{$\begin{array}{l}\text { Rate of BCS } \\
(\%)\end{array}$} & \multicolumn{2}{|c|}{$\begin{array}{l}\text { Local recurrence } \\
\text { after BCS }(\%)\end{array}$} & \multicolumn{2}{|c|}{$\begin{array}{l}\text { Overall survival at median } \\
\text { follow-up }(\%)\end{array}$} & \multicolumn{2}{|c|}{$\begin{array}{l}\text { Disease-free } \\
\text { survival }(\%)\end{array}$} \\
\hline & & & & & $\begin{array}{l}\text { Preop } \\
\text { CTX }\end{array}$ & $\begin{array}{l}\text { Postop } \\
\text { CTX }\end{array}$ & $\begin{array}{l}\text { Preop } \\
\text { CTX }\end{array}$ & $\begin{array}{l}\text { Postop } \\
\text { CTX }\end{array}$ & $\begin{array}{l}\text { Preop } \\
\text { CTX }\end{array}$ & $\begin{array}{l}\text { Postop } \\
\text { CTX }\end{array}$ & $\begin{array}{l}\text { Preop } \\
\text { CTX }\end{array}$ & $\begin{array}{l}\text { Postop } \\
\text { CTX }\end{array}$ \\
\hline $\begin{array}{l}\text { Institut Bergonie } \\
{[22,23]}\end{array}$ & 272 & II-IIIa & $\begin{array}{l}\text { E, Mth, V, Mt, } \\
\text { Th, Vd }\end{array}$ & $124 \mathrm{~m}$ & 63.1 & - & 22.5 & NA & 55.0 & 55.0 & NA & NA \\
\hline $\begin{array}{c}\text { Institut Curie } \\
{[21,24,25]}\end{array}$ & 414 & IIa-IIIa & $\mathrm{F}, \mathrm{A}, \mathrm{C}$ & $66 \mathrm{~m}$ & 82.0 & 77.0 & 24 & 18 & 86.0 & 78.0 & 73.0 & 68.0 \\
\hline $\begin{array}{l}\text { Royal Marsden } \\
\text { [26-28] }\end{array}$ & 309 & I-IIIIb & $\begin{array}{l}\text { Mx, Mt, } \\
\text { Mth, Tam }\end{array}$ & $48 \mathrm{~m}$ & 89.0 & 78.0 & 3 & 4 & 80.0 & 80.0 & 84.1 & 81.6 \\
\hline $\begin{array}{l}\text { N.N. Petrov } \\
\text { Research Institute } \\
\text { of Oncology [29] }\end{array}$ & 271 & IIb-IIIa & $\mathrm{Th}, \mathrm{M}, \mathrm{F}$ & $53 \mathrm{~m}$ & - & - & - & - & 86.0 & 78.3 & 81.0 & 71.6 \\
\hline $\begin{array}{c}\text { NSABP B-18 } \\
{[14,15,68]}\end{array}$ & 1523 & I-IIIIa & $\mathrm{A}, \mathrm{C}$ & $108 \mathrm{~m}$ & 60.0 & 68.0 & 10.7 & 7.6 & 69.0 & 70.0 & 53.0 & 55.0 \\
\hline EORTC [32] & 698 & I-IIIIa & $\mathrm{F}, \mathrm{E}, \mathrm{C}$ & $56 \mathrm{~m}$ & 37.0 & 21.0 & 18.1 & 11.9 & 82.0 & 84.0 & 65.0 & 70.0 \\
\hline $\begin{array}{l}\text { Gazet et al, } 2001 \\
{[30]}\end{array}$ & 210 & $\begin{array}{l}\text { T1-T4 } \\
\text { No-N2 }\end{array}$ & $\begin{array}{l}\text { Mth, Mx, } \\
\text { Mt }+ \text { gosrelin, } \\
\text { formestane }\end{array}$ & $60 \mathrm{~m}$ & 65.0 & 87.3 & - & - & 79.0 & 87.0 & - & - \\
\hline $\begin{array}{l}\text { Danforth et al, } 2003 \\
\text { [31] }\end{array}$ & 53 & II & $\begin{array}{l}\mathrm{F}, \mathrm{L}, \mathrm{A}, \mathrm{C} \\
\quad \mathrm{G}-\mathrm{CSF}\end{array}$ & 9 years & 42.3 & 40.7 & - & - & 88.5 & 77.8 & 65.4 & 59.3 \\
\hline
\end{tabular}

Abbreviations: A, doxorubicin; C, cyclophosphamide; Doc, docataxel; E, epirubicin; EROTC, European Organization for the Research and Treatment of Cancer; F, flourouracil; G-CSF, granulocyte colony stimulating factors; L, leucovorin; Mt, mitomycin; Mth, methotrexate; Mx, mitoxantrone; P, prednisolone; Preop, preoperative; Postop, postoperative; Tam, tamoxifen; Th, thiopeta; V, vincristine; Vd, vindesine. 
poor histological grade, and the failure to respond to preoperative chemotherapy [21].

\section{Neoadjuvant chemotherapy and use of breast-conserving surgery}

One of the most important benefits of neoadjuvant chemotherapy is that it offers tumor down-staging, expanding the number of women eligible for BCS. Typically, tumors $4 \mathrm{~cm}$ in size or less are best suited for BCS, but the cosmetic results improve with smaller tumors. Several large randomized controlled trials have reported the effect of neoadjuvant chemotherapy on rates of $\mathrm{BCS}$; these are summarized in Table 1.

Investigators for the NSABP B-18 trial reported that women who received preoperative chemotherapy were significantly more likely to receive a lumpectomy compared with women who received adjuvant therapy $(60 \%$ versus $67 \%, P<.002)$, with the greatest increase in lumpectomy rates among women who had tumors larger than $5 \mathrm{~cm}$ [15]. Other authors have studied BCS in the setting of neoadjuvant chemotherapy with comparable results. From these studies, detailed in Table 1 [22-31], the rates of BCS range from $37 \%$ to $89 \%$, but in general are higher among women who received neoadjuvant chemotherapy. In fact, approximately one-quarter of women who are not initially eligible for BCS, but who receive neoadjuvant chemotherapy, may safely receive BCS following chemotherapy because of tumor shrinkage [32]. Singletary and colleagues [33] reviewed the post-mastectomy pathology records of women who received neoadjuvant chemotherapy, and reported that up to $23 \%$ of women became potential BCS candidates based on based on resolution of skin changes, shrinkage of the primary tumor to less than $5 \mathrm{~cm}$, and the presence of unifocal disease; however, it remains challenging to accurately predict tumor size following neoadjuvant chemotherapy, with clinical examination and current imaging modalities such as mammography and ultrasound only moderately helpful in accurately predicting residual tumor size [34].

Nonetheless, BCS can be safely performed in women who receive neoadjuvant chemotherapy, with low rates of locoregional recurrence. Early studies documenting higher rates of breast tumor recurrence prompted skepticism in the ability of BCS to safely treat these women, with loco-regional recurrence rates ranging from $3-24 \%$ by ten years of follow-up (see Table 1) [35-37]. In general, reports of higher local recurrence rates were observed in women with inflammatory or locally advanced disease at presentation, and in patients where radiation-only was delivered as locoregional therapy (without surgery) after neoadjuvant chemotherapy.

Chen and colleagues [38] identified risk factors for loco-regional recurrence and developed selection criteria for women who will be best suited for BCS following neoadjuvant chemotherapy. In this study (a collective review of the M.D. Anderson Cancer Center experience with breast-conserving surgery after neoadjuvant chemotherapy), approximately $9 \%$ of women 
developed locoregional recurrence. Characteristics associated with increased likelihood of loco-regional recurrence included larger tumor sizes, advanced nodal disease, a multifocal pattern of residual disease following neoadjuvant chemotherapy, and the presence of lymphovascular invasion. The study authors propose the following contraindications for BCS following neoadjuvant chemotherapy: residual tumor size greater than $5 \mathrm{~cm}$, residual skin edema or direct skin involvement, chest wall fixation, diffuse calcifications on post-chemotherapy mammography, multicentric disease, and contraindications to medical therapy. Notably, T3 or T4 tumors did not have an increased risk of locoregional recurrence if another contraindication was not present.

\section{Diagnosis and management of axillary node metastases}

Introduced over 10 years ago, lymphatic mapping with SLN biopsy is a well-established alternative to axillary lymph node dissection (ALND) to diagnose axillary node metastases in women who have clinically nodenegative disease. Based on the concept that areas of the breast drain through different lymphatics to a "sentinel node," SLN biopsy uses either dye or a radioactive tracer to identify the axillary SLN, which can then be excised and examined for metastatic disease. Multiple studies have confirmed that the remainder of the axilla can be presumed to be disease-free if the sentinel node is free of disease, and full ALND is unnecessary. False-negative rates for SLN biopsy range from $1 \%$ to $10 \%$ [39-42]. Accurate and reliable assessment of the axillary lymph node basins is essential to identify axillary metastases in women who receive neoadjuvant chemotherapy, because most of these patients have locally advanced disease or large primary tumors, with a high likelihood of axillary metastases at diagnosis.

Both SLN biopsy and ultrasound- guided fine-needle aspiration (FNA) have been studied to detect axillary metastases before the initiation of preoperative chemotherapy. Ultrasound-guided FNA has been shown to be accurate and effective to detect and document axillary nodal disease, and aspiration of nonpalpable suspicious axillary lymph nodes is a reliable option for pre-chemotherapy staging of axillary disease [43]. Unfortunately, axillary ultrasound has a false-negative rate of $15-20 \%$, because of limited sensitivity in detecting metastatic foci smaller than 5-10 $\mathrm{mm}$. Many centers have therefore, opted to routinely perform a pre-neoadjuvant chemotherapy SLN biopsy. Not surprisingly, (given pre-existing experience with lymphatic mapping performed alongside primary breast surgery in early-stage breast cancer management) SLN biopsy before chemotherapy is both feasible and accurate to identify axillary metastases at time of disease presentation [44-46]. Results from these studies are detailed in Table 2. Identification of the SLN was performed without difficulty, and follow-up of those patients who were node-negative before chemotherapy has not revealed evidence of 
Table 2

Studies assessing the use of SLN biopsy in the setting of neoadjuvant chemotherapy

\begin{tabular}{|c|c|c|c|c|c|c|}
\hline Study & $\mathrm{N}$ & $\begin{array}{l}\text { Pre/ } \\
\text { postperative } \\
\text { chemotherapy }\end{array}$ & $\begin{array}{l}\text { Method of } \\
\text { lymphatic } \\
\text { mapping }\end{array}$ & $\begin{array}{l}\text { SLN } \\
\text { identified }\end{array}$ & $\begin{array}{l}\text { Metastases } \\
\text { in SLN only }\end{array}$ & $\begin{array}{l}\text { False } \\
\text { negative } \\
\text { rate }(\%)\end{array}$ \\
\hline $\begin{array}{l}\text { Schrenk } \\
\text { et al, } 2003 \text { [45] }\end{array}$ & 21 & Pre & $\begin{array}{l}\text { Dye alone, } \\
\text { dye + tracer }\end{array}$ & 100.0 & NA & NA \\
\hline $\begin{array}{l}\text { Sabel } \\
\quad \text { et al, } 2003 \text { [44] }\end{array}$ & 25 & Pre & Dye + tracer & 100.0 & NA & NA \\
\hline $\begin{array}{l}\text { Olilla et al, } \\
2005 \text { [46] }\end{array}$ & 21 & Pre & Dye + tracer & 100.0 & NA & NA \\
\hline $\begin{array}{l}\text { Breslin } \\
\quad \text { et al, } 2000 \text { [49] }\end{array}$ & 51 & Post & $\begin{array}{l}\text { Dye alone, } \\
\text { dye }+ \text { tracer }\end{array}$ & 84.3 & 45.5 & 12.0 \\
\hline $\begin{array}{l}\text { Nason } \\
\quad \text { et al, } 2000[50]\end{array}$ & 15 & Post & Dye + tracer & 86.7 & $\begin{array}{l}\text { Not } \\
\text { Reported }\end{array}$ & 33.0 \\
\hline $\begin{array}{l}\text { Schwartz } \\
2003[51]\end{array}$ & 21 & Post & Dye alone & 100.0 & 63.6 & 9.0 \\
\hline $\begin{array}{l}\text { Fernandez } \\
\quad \text { et al, } 2001 \text { [52] }\end{array}$ & 40 & Post & Tracer & 85.0 & 25.0 & 22.0 \\
\hline $\begin{array}{l}\text { Mamounas } \\
\text { et al, } 2005 \text { [65] }\end{array}$ & 428 & Post & $\begin{array}{l}\text { Dye alone, tracer, } \\
\text { dye + tracer }\end{array}$ & 84.8 & 56.0 & 10.7 \\
\hline $\begin{array}{l}\text { Julian } \\
\quad \text { et al, } 2002 \text { [53] }\end{array}$ & 34 & Post & $\begin{array}{l}\text { Dye alone, tracer, } \\
\text { dye }+ \text { tracer }\end{array}$ & 91.2 & 38.7 & 0 \\
\hline $\begin{array}{l}\text { Haid } \\
\text { et al, } 2001 \text { [54] }\end{array}$ & 33 & Post & Dye + tracer & 87.9 & 37.9 & 0 \\
\hline $\begin{array}{l}\text { Reitsamer } \\
\text { et al, } 2003 \text { [55] }\end{array}$ & 30 & Post & Dye + tracer & 86.7 & 57.1 & 6.7 \\
\hline $\begin{array}{l}\text { Aihara } \\
\quad \text { et al, } 2004 \text { [56] }\end{array}$ & 36 & Post & Dye alone & 100 & 0.0 & 8.0 \\
\hline $\begin{array}{l}\text { Kinoshita } \\
\text { et al, } 2006 \text { [57] }\end{array}$ & 77 & Post & Dye + tracer & 93.5 & 45.8 & 11.1 \\
\hline $\begin{array}{l}\text { Khan } \\
\text { et al, } 2005 \text { [47] }\end{array}$ & 38 & Post & Dye + tracer & 97.0 & 33.0 & 4.5 \\
\hline $\begin{array}{l}\text { Miller } \\
\quad \text { et al, } 2002 \text { [58] }\end{array}$ & 35 & Post & $\begin{array}{c}\text { Dye alone, tracer, } \\
\text { dye }+ \text { tracer }\end{array}$ & 86.0 & 22.2 & 0 \\
\hline $\begin{array}{l}\text { Tafra } \\
\text { et al, } 2001 \text { [59] }\end{array}$ & 29 & Post & Dye + tracer & 93.0 & - & 0 \\
\hline $\begin{array}{l}\text { Balch } \\
\quad \text { et al, } 2003 \text { [60] }\end{array}$ & 32 & Post & Dye + tracer & 97.0 & 55 & 5 \\
\hline $\begin{array}{l}\text { Brady } \\
\quad \text { et al, } 2002[61]\end{array}$ & 14 & Post & $\begin{array}{l}\text { Dye alone, } \\
\text { tracer alone (1) }\end{array}$ & 93.0 & 60.0 & 0 \\
\hline $\begin{array}{l}\text { Stearns } \\
\quad \text { et al, } 2002 \text { [67] }\end{array}$ & 34 & Post & Dye alone & 85.3 & 14.7 & 14.0 \\
\hline $\begin{array}{l}\text { Piato } \\
\text { et al, } 2003 \text { [62] }\end{array}$ & 42 & Post & Tracer & 97.6 & - & 11.5 \\
\hline $\begin{array}{l}\text { Shimazu } \\
\text { et al, } 2004 \text { [63] }\end{array}$ & 42 & Post & $\begin{array}{l}\text { Dye alone, } \\
\text { Tracer, } \\
\text { Dye + tracer }\end{array}$ & 94.0 & 31.0 & 12.1 \\
\hline $\begin{array}{l}\text { Jones } \\
\text { et al, } 2005 \text { [64] }\end{array}$ & 36 & Post & - & 80.6 & 16.7 & 11.0 \\
\hline
\end{tabular}

Abbreviation: NA, not applicable. 
recurrent disease. Furthermore, Ollila and colleagues [46] included routine completion ALND (after neoadjuvant chemotherapy) into the surgical management plan of all cases undergoing SLN biopsy prior to neoadjuvant therapy, regardless of whether or not this initial staging SLN was negative or positive. This study confirmed that patients staged as node-negative by preneoadjuvant chemotherapy SLN biopsy will remain node-negative, as the completion ALND revealed no metastatic disease in this subset of cases. Results from these pre-neoadjuvant chemotherapy SLN biopsy studies therefore suggest that patients who are node-negative by ultrasound-guided FNA or SLN biopsy may not require further axillary surgery [44-47]; however, future studies with long-term follow-up of these patients are needed to fully resolve this question.

An alternative approach involves performing the SLN biopsy after neoadjuvant chemotherapy, so that patients can avoid the additional operative procedure, and so that focus can be placed upon the final, post-neoadjuvant chemotherapy downstaged disease status. SLN biopsy following neoadjuvant chemotherapy has been met with controversy. Some postulate that SLN biopsy will only be accurate if the metastatic deposits within each axillary lymph node respond in the same way to preoperative chemotherapy. Additionally, tumor cells that necrose because of chemotherapy may block axillary lymphatics, causing impaired flow of the dye or tracer to the sentinel node, and shrinkage of the primary tumor may distort lymphatic drainage patterns. Furthermore, large primary tumors may drain to multiple lymph node basins, and it is not known if neoadjuvant chemotherapy would. Finally, neoadjuvant chemotherapy could potentially complicate subsequent ALND [39]. Neuman and colleagues [48] have reported that fewer lymph nodes are retrieved during ALND performed in patients who have received neoadjuvant chemotherapy, making it difficult to assess if a complete and therapeutic procedure has been performed.

Despite these concerns, SLN biopsy has been shown to be both accurate and feasible in women who receive neoadjuvant chemotherapy. These studies are detailed in Table 2 [49-64]. Early studies evaluating the use of SLN biopsy among women receiving neoadjuvant chemotherapy were limited by small sample size and single-center setting. Although estimates from these early studies vary widely, the collective data indicate that SLN biopsy among women receiving neoadjuvant chemotherapy has similar success in identifying the sentinel node, and similar false-negative rates as compared with SLN biopsy in women who receive adjuvant chemotherapy. SLN identification rates range from $80 \%$ to $100 \%$, and false-negative rates range from $0 \%$ to $33 \%$. The NSABP protocol B-27 is a clinical trial of neoadjuvant chemotherapy, however, it includes a large cohort of women that underwent SLN biopsy with completion ALND following delivery of the neoadjuvant therapy. In this study, false-negative rates were comparable to those reported in multicenter studies of women who have early-stage breast cancer treated with adjuvant chemotherapy. The NSABP authors 
report a SLN identification rate of $84.8 \%$, and a false-negative rate of $10.7 \%$ [65]. Box 1 summarizes the advantages and disadvantages of performing a SLN biopsy before versus after delivery of neoadjuvant chemotherapy. Primary disadvantages of the pre-neoadjuvant chemotherapy strategy are related to the need for an additional operative procedure, and the concern that many women whose initial SLN reveals metastatic disease

Box 1. Advantages and disadvantages of sentinel lymph node biopsy performed before versus delivery of neoadjuvant chemotherapy

Sentinel lymph node (SLN) biopsy performed after delivery of neoadjuvant chemotherapy

Advantages

- Among neoadjuvant chemotherapy patients, there is more widespread experience with lymphatic mapping performed after chemotherapy, because breast and axillary surgery typically have been performed concomitantly upon completion of preoperative chemotherapy.

- Surgical sequence consistent with conventional neoadjuvant chemotherapy regimens

Disadvantages

- False-negative rates not yet optimized-range, $0 \%$ to $40 \%$

- Significant learning curve

SLN biopsy performed before delivery of neoadjuvant chemotherapy

Advantages

- Significance of nodal status is understood better when axillary staging is performed at presentation.

- Preferred by many medical and radiation oncologists, who may modify their treatment recommendations on the basis of pretreatment nodal status

- Most surgeons already experienced with lymphatic mapping technology in the prechemotherapy setting

Disadvantages

- Commits some patients to unnecessary ALND (metastatic disease limited to the excised SLN in $30 \%$ to $50 \%$; chemotherapy downstages $25 \%$ to $30 \%$ of patients to node negativity)

- Requires an additional surgical procedure 
will then be subjected to an "unnecessary" ALND. The unnecessary ALNDs (completion ALNDs that are negative for residual axillary disease) might occur because the initial metastatic disease was limited to the resected SLN, or because the neoadjuvant chemotherapy sterilized all residual axillary metastases. Primary concerns regarding the post-neoadjuvant chemotherapy approach are related to skepticism regarding accuracy of lymphatic mapping in this setting. Also, many oncologists believe that definitive axillary staging information at presentation is just as important as knowing the definitive post-treatment stage. At the University of Michigan, we approach the axilla of neoadjuvant chemotherapy patients in a comprehensive fashion, allowing us to stratify patients into three different categories: node-negative cases at presentation; node-positive cases at presentation, that are downstaged to node-negative; and node-positive cases with resistent disease, that remains node-positive. We accomplish this stratification by performing pre-chemotherapy axillary ultrasound and ultrasound-guided FNA biopsy of any suspicious nodes. If the ultrasound is negative, then we proceed with definitive axillary staging by SLN biopsy. Definitively-node-negative cases do not undergo any additional axillary surgery after the neoadjuvant chemotherapy has been delivered. Node-positive cases undergo completion ALND after the neoadjuvant chemotherapy has been delivered, but we have been coupling this final ALND with a SLN biopsy, so that the accuracy of lymphatic mapping for identifying downstaged patients can be defined. The authors' results $[47,66]$ thus far have been promising: our low false negative rate of $8 \%$ suggests that the SLN biopsy may be a reasonable strategy for assessing the final axillary stage and determining which of the initially node-positive cases have had their axillae sterilized and can therefore avoid the completion ALND.

SLN biopsy may not be appropriate for all patients receiving neoadjuvant chemotherapy, however. Stearns and colleagues [67] studied the use of SLN biopsy in women who received neoadjuvant chemotherapy in the setting of inflammatory breast cancer. These authors reports that the SLN was identified successfully in only $75 \%$ of women, compared with $89 \%$ in women who had locally advanced, but not inflammatory, disease. Although the study had a relatively small sample size, it does raise concern that SLN biopsy is excessively risky for patients who have inflammatory breast cancer.

In addition to offering complete pathologic response at the primary tumor, neoadjuvant chemotherapy can clear the axilla of nodal metastases before surgery in some patients $[14,68,69]$. Among women who have known axillary metastases, neoadjuvant chemotherapy has been shown to offer complete pathologic response in the axilla in up to $23 \%$ of these patients. These patients have a higher 5 -year overall survival and disease-free survival compared with patients who do not achieve a complete pathologic response $[70,71]$. Unfortunately, for women who have persistent extensive nodal disease burden following neoadjuvant chemotherapy, the median survival is poor at 48 months, with a 10 -year survival rate of $26 \%$ [72]. Predictors of 
complete conversion to node-negative disease are estrogen-receptor negative tumors, smaller primary tumors, and complete pathologic response in the primary tumor. These patients have significantly longer 5-year disease-free survival rates compared with patients who have residual disease $(87 \%$ versus $51 \%)[70,73,74]$.

\section{Summary}

Neoadjuvant chemotherapy is standard management for women who have locally advanced or inflammatory breast cancer, but can also be considered for any case of early-stage breast cancer, if it is clear that postoperative would be administered. postoperative chemotherapy for early-stage breast cancer. Disease-free survival and overall survival are equivalent between patients treated with neoadjuvant chemotherapy and patients treated with the same regimen postoperatively. Preoperative chemotherapy can offer women less morbid surgical treatment by down-staging both the primary breast tumor and axillary metastases. Finally, response to chemotherapy can inform clinicians of the chemosensitivity of the tumor, and predict long-term outcome for women who have breast cancer. Use of neoadjuvant endocrine therapy and neoadjuvant therapy with targeted agents is currently being studied. The optimal strategy for incorporating lymphatic mapping into neoadjuvant therapy regimens has not yet been uniformly defined.

\section{References}

[1] Kaufmann M, Hortobagyi GN, Goldhirsch A, et al. Recommendations from an international expert panel on the use of neoadjuvant (primary) systemic treatment of operable breast cancer: an update. J Clin Oncol 2006;24(12):1940-9.

[2] Cristofanilli M, Gonzalez-Angulo A, Sneige N, et al. Invasive lobular carcinoma classic type: response to primary chemotherapy and survival outcomes. J Clin Oncol 2005;23(1):41-8.

[3] Newman LA, Buzdar AU, Singletary SE, et al. A prospective trial of preoperative chemotherapy in resectable breast cancer: predictors of breast-conservation therapy feasibility. Ann Surg Oncol 2002;9(3):228-34.

[4] Bear HD, Anderson S, Brown A, et al. The effect on tumor response of adding sequential preoperative docetaxel to preoperative doxorubicin and cyclophosphamide: preliminary results from National Surgical Adjuvant Breast and Bowel Project Protocol B-27. J Clin Oncol 2003;21(22):4165-74.

[5] Bear HD, Anderson S, Smith RE, et al. Sequential preoperative or postoperative docetaxel added to preoperative doxorubicin plus cyclophosphamide for operable breast cancer: National Surgical Adjuvant Breast and Bowel Project Protocol B-27. J Clin Oncol 2006;24(13): 2019-27.

[6] Smith IC, Heys SD, Hutcheon AW, et al. Neoadjuvant chemotherapy in breast cancer: significantly enhanced response with docetaxel. J Clin Oncol 2002;20(6):1456-66.

[7] Hamilton A, Hortobagyi G. Chemotherapy: what progress in the last 5 years? J Clin Oncol 2005;23(8):1760-75.

[8] Dixon JM, Jackson J, Renshaw L, et al. Neoadjuvant tamoxifen and aromatase inhibitors: comparisons and clinical outcomes. J Steroid Biochem Mol Biol 2003;86(3-5):295-9. 
[9] Ellis MJ, Coop A, Singh B, et al. Letrozole is more effective neoadjuvant endocrine therapy than tamoxifen for ErbB-1- and/or ErbB-2-positive, estrogen receptor-positive primary breast cancer: evidence from a Phase III randomized trial. J Clin Oncol 2001;19(18):3808-16.

[10] Eiermann W, Paepke S, Appfelstaedt J, et al. Preoperative treatment of postmenopausal breast cancer patients with letrozole: a randomized double-blind multicenter study. Ann Oncol 2001;12(11):1527-32.

[11] von Minckwitz G, Costa SD, Raab G, et al. Dose-dense doxorubicin, docetaxel, and granulocyte colony-stimulating factor support with or without tamoxifen as preoperative therapy in patients with operable carcinoma of the breast: a randomized, controlled, open Phase IIb study. J Clin Oncol 2001;19(15):3506-15.

[12] Abrial C, Mouret-Reynier MA, Cure H, et al. Neoadjuvant endocrine therapy in breast cancer. Breast 2006;15(1):9-19.

[13] American College of Surgeons Oncology Group Protocol Z1031. Available at: www. acosog.org. Accessed April 1, 2007.

[14] Wolmark N, Wang J, Mamounas E, et al. Preoperative chemotherapy in patients with operable breast cancer: nine-year results from National Surgical Adjuvant Breast and Bowel Project B-18. J Natl Cancer Inst Monogr 2001;(30):96-102.

[15] Fisher B, Brown A, Mamounas E, et al. Effect of preoperative chemotherapy on localregional disease in women with operable breast cancer: findings from National Surgical Adjuvant Breast and Bowel Project B-18. J Clin Oncol 1997;15(7):2483-93.

[16] Mauri D, Pavlidis N, Ioannidis JP. Neoadjuvant versus adjuvant systemic treatment in breast cancer: a meta-analysis. J Natl Cancer Inst 2005;97(3):188-94.

[17] Kuerer HM, Newman LA, Smith TL, et al. Clinical course of breast cancer patients with complete pathologic primary tumor and axillary lymph node response to doxorubicin-based neoadjuvant chemotherapy. J Clin Oncol 1999;17:460-9.

[18] von Minckwitz G, Raab G, Caputo A, et al. Doxorubicin with cyclophosphamide followed by docetaxel every 21 days compared with doxorubicin and docetaxel every 14 days as preoperative treatment in operable breast cancer: the GEPARDUO study of the German Breast Group. J Clin Oncol 2005;23(12):2676-85.

[19] von Minckwitz G, Blohmer JU, Raab G, et al. In vivo chemosensitivity-adapted preoperative chemotherapy in patients with early-stage breast cancer: the GEPARTRIO pilot study. Ann Oncol 2005;16(1):56-63.

[20] Feldman LD, Hortobagyi GN, Buzdar AU, et al. Pathological assessment of response to induction chemotherapy in breast cancer. Cancer Res 1986;46(5):2578-81.

[21] Scholl SM, Fourquet A, Asselain B, et al. Neoadjuvant versus adjuvant chemotherapy in premenopausal patients with tumours considered too large for breast conserving surgery: preliminary results of a randomised trial: S6. Eur J Cancer 1994;30(5):645-52.

[22] Mauriac L, MacGrogan G, Avril A, et al. Neoadjuvant chemotherapy for operable breast carcinoma larger than $3 \mathrm{~cm}$ : a unicentre randomized trial with a 124-month median follow-up. Institut Bergonie Bordeaux Groupe Sein (IBBGS). Ann Oncol 1999;10(1):47-52.

[23] Mauriac L, Durand M, Avril A, et al. Effects of primary chemotherapy in conservative treatment of breast cancer patients with operable tumors larger than $3 \mathrm{~cm}$. Results of a randomized trial in a single centre. Ann Oncol 1991;2(5):347-54.

[24] Scholl SM, Asselain B, Palangie T, et al. Neoadjuvant chemotherapy in operable breast cancer. Eur J Cancer 1991;27(12):1668-71.

[25] Scholl SM, Pierga JY, Asselain B, et al. Breast tumour response to primary chemotherapy predicts local and distant control as well as survival. Eur J Cancer 1995;31(12):1969-75.

[26] Powles TJ, Hickish TF, Makris A, et al. Randomized trial of chemoendocrine therapy started before or after surgery for treatment of primary breast cancer. J Clin Oncol 1995; 13(3):547-52.

[27] Makris A, Powles TJ, Ashley SE, et al. A reduction in the requirements for mastectomy in a randomized trial of neoadjuvant chemoendocrine therapy in primary breast cancer. Ann Oncol 1998;9(11):1179-84. 
[28] Makris A, Powles TJ, Dowsett M, et al. Prediction of response to neoadjuvant chemoendocrine therapy in primary breast carcinomas. Clin Cancer Res 1997;3(4):593-600.

[29] Semiglazov VF, Topuzov EE, Bavli JL, et al. Primary (neoadjuvant) chemotherapy and radiotherapy compared with primary radiotherapy alone in Stage IIb-IIIa breast cancer. Ann Oncol 1994;5(7):591-5.

[30] Gazet JC, Ford HT, Gray R, et al. Estrogen-receptor-directed neoadjuvant therapy for breast cancer: results of a randomised trial using formestane and methotrexate, mitozantrone and mitomycin C (MMM) chemotherapy. Ann Oncol 2001;12(5):685-91.

[31] Danforth DN Jr, Cowan K, Altemus R, et al. Preoperative FLAC/granulocyte-colony-stimulating factor chemotherapy for Stage II breast cancer: a prospective randomized trial. Ann Surg Oncol 2003;10(6):635-44.

[32] van der Hage JA, van de Velde CJ, Julien JP, et al. Preoperative chemotherapy in primary operable breast cancer: results from the European Organization for Research and Treatment of Cancer trial 10902. J Clin Oncol 2001;19(22):4224-37.

[33] Singletary SE, McNeese MD, Hortobagyi GN. Feasibility of breast-conservation surgery after induction chemotherapy for locally advanced breast carcinoma. Cancer 1992;69(11): $2849-52$.

[34] Chagpar AB, Middleton LP, Sahin AA, et al. Accuracy of physical examination, ultrasonography, and mammography in predicting residual pathologic tumor size in patients treated with neoadjuvant chemotherapy. Ann Surg 2006;243(2):257-64.

[35] Touboul E, Lefranc JP, Blondon J, et al. Primary chemotherapy and preoperative irradiation for patients with Stage II larger than $3 \mathrm{~cm}$ or locally advanced non-inflammatory breast cancer. Radiother Oncol 1997;42(3):219-29.

[36] Rouzier R, Extra JM, Carton M, et al. Primary chemotherapy for operable breast cancer: incidence and prognostic significance of ipsilateral breast tumor recurrence after breastconserving surgery. J Clin Oncol 2001;19(18):3828-35.

[37] Calais G, Berger C, Descamps P, et al. Conservative treatment feasibility with induction chemotherapy, surgery, and radiotherapy for patients with breast carcinoma larger than 3 cm. Cancer 1994;74(4):1283-8.

[38] Chen AM, Meric-Bernstam F, Hunt KK, et al. Breast conservation after neoadjuvant chemotherapy: the MD Anderson cancer center experience. J Clin Oncol 2004;22(12): 2303-12.

[39] Kuerer HM, Newman LA. Lymphatic mapping and sentinel lymph node biopsy for breast cancer: developments and resolving controversies. J Clin Oncol 2005;23(8): $1698-705$.

[40] Krag DN, Weaver DL, Alex JC, et al. Surgical resection and radiolocalization of the sentinel lymph node in breast cancer using a gamma probe. Surg Oncol 1993;2(6):335-9 [discussion: 40].

[41] Schwartz GF. Clinical practice guidelines for the use of axillary sentinel lymph node biopsy in carcinoma of the breast: current update. Breast J 2004;10(2):85-8.

[42] Senn HJ, Thurlimann B, Goldhirsch A, et al. Comments on the St. Gallen Consensus 2003 on the primary therapy of early breast cancer. Breast 2003;12(6):569-82.

[43] Krishnamurthy S, Sneige N, Bedi DG, et al. Role of ultrasound-guided fine-needle aspiration of indeterminate and suspicious axillary lymph nodes in the initial staging of breast carcinoma. Cancer 2002;95(5):982-8.

[44] Sabel MS, Schott AF, Kleer CG, et al. Sentinel node biopsy prior to neoadjuvant chemotherapy. Am J Surg 2003;186(2):102-5.

[45] Schrenk P, Hochreiner G, Fridrik M, et al. Sentinel node biopsy performed before preoperative chemotherapy for axillary lymph node staging in breast cancer. Breast J 2003;9(4): $282-7$.

[46] Ollila DW, Neuman HB, Sartor C, et al. Lymphatic mapping and sentinel lymphadenectomy prior to neoadjuvant chemotherapy in patients with large breast cancers. Am J Surg 2005; 190:371-5. 
[47] Khan A, Sabel MS, Nees A, et al. Comprehensive axillary evaluation in neoadjuvant chemotherapy patients with ultrasonography and sentinel lymph node biopsy. Ann Surg Oncol 2005;12(9):697-704.

[48] Neuman H, Carey LA, Ollila DW, et al. Axillary lymph node count is lower after neoadjuvant chemotherapy. Am J Surg 2006;191(6):827-9.

[49] Breslin TM, Cohen L, Sahin A, et al. Sentinel lymph node biopsy is accurate after neoadjuvant chemotherapy for breast cancer. J Clin Oncol 2000;18(20):3480-6.

[50] Nason KS, Anderson BO, Byrd DR, et al. Increased false negative sentinel node biopsy rates after preoperative chemotherapy for invasive breast carcinoma. Cancer 2000;89(11): 2187-94.

[51] Schwartz GF, Meltzer AJ. Accuracy of axillary sentinel lymph node biopsy following neoadjuvant (induction) chemotherapy for carcinoma of the breast. Breast J 2003;9(5):374-9.

[52] Fernandez A, Cortes M, Benito E, et al. Gamma probe sentinel node localization and biopsy in breast cancer patients treated with a neoadjuvant chemotherapy scheme. Nucl Med Commun 2001;22(4):361-6.

[53] Julian TB, Dusi D, Wolmark N. Sentinel node biopsy after neoadjuvant chemotherapy for breast cancer. Am J Surg 2002;184(4):315-7.

[54] Haid A, Tausch C, Lang A, et al. Is sentinel lymph node biopsy reliable and indicated after preoperative chemotherapy in patients with breast carcinoma? Cancer 2001;92(5):1080-4.

[55] Reitsamer R, Peintinger F, Rettenbacher L, et al. Sentinel lymph node biopsy in breast cancer patients after neoadjuvant chemotherapy. J Surg Oncol 2003;84(2):63-7.

[56] Aihara T, Munakata S, Morino H, et al. Feasibility of sentinel node biopsy for breast cancer after neoadjuvant endocrine therapy: a pilot study. J Surg Oncol 2004;85(2):77-81.

[57] Kinoshita T, Takasugi M, Iwamoto E, et al. Sentinel lymph node biopsy examination for breast cancer patients with clinically negative axillary lymph nodes after neoadjuvant chemotherapy. Am J Surg 2006;191(2):225-9.

[58] Miller AR, Thomason VE, Yeh IT, et al. Analysis of sentinel lymph node mapping with immediate pathologic review in patients receiving preoperative chemotherapy for breast carcinoma. Ann Surg Oncol 2002;9(3):243-7.

[59] Tafra L, Verbanac KM, Lannin DR. Preoperative chemotherapy and sentinel lymphadenectomy for breast cancer. Am J Surg 2001;182(4):312-5.

[60] Balch GC, Mithani SK, Richards KR, et al. Lymphatic mapping and sentinel lymphadenectomy after preoperative therapy for Stage II and III breast cancer. Ann Surg Oncol 2003; 10(6):616-21.

[61] Brady EW. Sentinel lymph node mapping following neoadjuvant chemotherapy for breast cancer. Breast J 2002;8(2):97-100.

[62] Piato JR, Barros AC, Pincerato KM, et al. Sentinel lymph node biopsy in breast cancer after neoadjuvant chemotherapy. A pilot study. Eur J Surg Oncol 2003;29(2):118-20.

[63] Shimazu K, Tamaki Y, Taguchi T, et al. Sentinel lymph node biopsy using periareolar injection of radiocolloid for patients with neoadjuvant chemotherapy-treated breast carcinoma. Cancer 2004;100(12):2555-61.

[64] Jones JL, Zabicki K, Christian RL, et al. A comparison of sentinel node biopsy before and after neoadjuvant chemotherapy: timing is important. Am J Surg 2005;190(4):517-20.

[65] Mamounas EP, Brown A, Anderson S, et al. Sentinel node biopsy after neoadjuvant chemotherapy in breast cancer: results from National Surgical Adjuvant Breast and Bowel Project Protocol B-27. J Clin Oncol 2005;23(12):2694-702.

[66] Newman EA, Sabel M, Nees A, et al. Sentinel lymph node biopsy following neoadjuvant chemotherapy is Accurate in patients with documented nodal metastases at presentation. Ann Surg Onc, in press.

[67] Stearns V, Ewing CA, Slack R, et al. Sentinel lymphadenectomy after neoadjuvant chemotherapy for breast cancer may reliably represent the axilla except for inflammatory breast cancer. Ann Surg Oncol 2002;9(3):235-42. 
[68] Singletary SE. Neoadjuvant chemotherapy in the treatment of Stage II and III breast cancer. Am J Surg 2001;182(4):341-6.

[69] Fisher B, Bryant J, Wolmark N, et al. Effect of preoperative chemotherapy on the outcome of women with operable breast cancer. J Clin Oncol 1998;16(8):2672-85.

[70] Kuerer HM, Sahin AA, Hunt KK, et al. Incidence and impact of documented eradication of breast cancer axillary lymph node metastases before surgery in patients treated with neoadjuvant chemotherapy. Ann Surg 1999;230(1):72-8.

[71] Hennessy BT, Hortobagyi GN, Rouzier R, et al. Outcome after pathologic complete eradication of cytologically proven breast cancer axillary node metastases following primary chemotherapy. J Clin Oncol 2005;23(36):9304-11.

[72] Pierga JY, Mouret E, Dieras V, et al. Prognostic value of persistent node involvement after neoadjuvant chemotherapy in patients with operable breast cancer. Br J Cancer 2000;83(11): $1480-7$.

[73] Kuerer HM, Newman LA, Smith TL, et al. Clinical course of breast cancer patients with complete pathologic primary tumor and axillary lymph node response to doxorubicin-based neoadjuvant chemotherapy. J Clin Oncol 1999;17(2):460-9.

[74] Lenert JT, Vlastos G, Mirza NQ, et al. Primary tumor response to induction chemotherapy as a predictor of histological status of axillary nodes in operable breast cancer patients. Ann Surg Oncol 1999;6(8):762-7. 